\title{
Application of Interactive Design in Museum Exhibition
}

\author{
Lifen Weng \\ Xiamen University of Technology \\ Xiamen, China
}

\begin{abstract}
As nonprofit permanent institutions, museums are open to the public for learning, education and entertainment and serve the social development. Traditional museums mainly display static objects. The transmission efficiency of museum information is greatly influenced. The deficiencies of exhibition ways in traditional museum are analyzed to discuss the feasibility of applying interactive design in museum exhibition.
\end{abstract}

Keywords-interactive design; museum; exhibition design

\section{INTRODUCTION}

Museum collects, displays and researches objects related to nature and cultural heritage of human and classifies scientific, historical articles with artistic value, referring to institutions, buildings, places or social public institutions providing knowledge, education and appreciation. It is proposed on the tenth session of International Council of Museums held in Copenhagen that "museum is a nonprofit permanent public institution to serve the society and social development, carrying out collection, protection, research, transmission and exhibition of articles witnessing human and human environment for research, education and appreciation." [1]As a nonprofit permanent institution, museums are open to the public, serving the social development for learning, education and recreation. Traditional museums mainly display static objects. The deficiencies of exhibition ways in traditional museum are analyzed to discuss the application of interactive design in exhibition design of museums.

\section{DEFICIENCIES OF EXHIBITION WAYS IN TRADITIONAL MUSEUMS}

Traditional museums use window display "with objects as the top priority". It fails to arouse visitors' subjective initiative because they only receive information passively. The cultural accomplishment of visitors cannot be improved, directly influencing the transmission efficiency of cultural information in museums.

\section{A. Exhibition with Objects as the Top Priority}

Traditional museums mainly collect and display objects representing nature and cultural heritage of human. It neglects the ability of human as the main participator to understand and absorb information. Visitors receive the information through objects passively. The transmission efficiency of information is greatly influenced. Most visitors only give a hurried and cursory glance at these objects that fail to leave a deep impression on them. It has little effect to improve visitors' cultural accomplishments.

\section{B. Exhibition Focusing on Static Objects}

Traditional museums use window display for objects and lack interaction with visitors. It is difficult to truly attract visitors' interests through "duck-stuffing" type of exhibition. Visitors passively and rigidly receive information of exhibits. The transmission efficiency of information from exhibits will be discounted.

\section{SIGNIFICANCE OF INTERACTIVE DESIGN IN EXHIBITION DESIGN OF MUSEUMS}

It is proposed in Concise Encyclopedia Britannica that: modern museums are institutions of cultural education collecting, displaying and researching objects related to nature and human, in order to provide knowledge, education and appreciation for the public. Therefore, under the premise of ensuring the safety of exhibits, it is of vital importance to furthest provide knowledge and transmit culture for the public. In order to obtain good effects, the traditional exhibition ways in museums should be altered to carry out interaction with visitors. Interactive design has immeasurable significance for the interaction between exhibits and human.

"Interactive design" is first defined in computer field and has expanded to an interdisciplinary research scope at present. In a narrow sense, it refers to direct or indirect communication process between human and equipment, system and websites. "Interactive design" means the design of interactive products to support people's daily work and life. [2] In a broad sense, interaction refers to the interactive influence of all existences. Interactive Design is "the design of space for human communication and interaction". [3] The interactive design in exhibition design of museums mainly refers to the stories of objects and the interaction with visitors, in order to make visitors become active participators to explore and think and have profound experience instead of passively receiving information about exhibits. 


\section{IMPLEMENTATION WAYS OF INTERACTIVE DESIGN IN EXHIBITION DESIGN OF MUSEUMS}

\section{A. Exhibition of Scene Interactiion}

Scene interactive exhibition changes static exhibition into dynamic exhibition and makes museum exhibition more recreational and interesting. It guides visitors to know stories about exhibits and better understand its cultural connotation. Meanwhile, it leaves deep impression on visitors.

For example, in the human pavilion of Smithsonian National Museum of Natural History, multimedia are used in the entrance to display with transformation of characters in various years as the background, letting visitors as if enter the time tunnel and bringing them back to the prehistoric era. It is natural and easier for visitors to accept the introduction to figures. In the period of time tunnel, questions are raised for visitors before visiting, altering passive information acceptance as active information exploration. A very interesting interactive device exists in the third floor of Cooper Hewitt Smithsonians design museum in New York of America. Visitors can design patterns on the multimedia interactive screen. It is projected on the two huge screens to let visitors have visualized experience. Visitors can take photos with patterns designed by them or store it in the scanner provided by the museum. They can $\log$ in the website and query all information stored in the scanner previously through individual coding on the entrance ticket or share it on public platforms for take it as computer desktop.

The scene interactive exhibition makes it more amusing to visit museums, altering one-way information transmission to two-way information interaction. Visitors are stimulated to take the initiative to acquire information instead of receiving information passively. It greatly increases the amount of information accepted by visitors.

\section{B. Exhibition of Man-Machine Interaction}

The man-machine interactive exhibition in Cooper Hewitt Smithsonians design museum of America is worthy of our learning. It has two merits. The first is the scanner provided for visitors to store exhibit information. Visitors are provided with a scanner and an individual password (scanner should be put in the recycling bins when visitors leave the museum) by Cooper Hewitt Smithsonians design museum when buying tickets at the entrance. It is convenient for visitors to acquire information in which they are interested when visiting and read later. The scanner can paint on the interactive screen in the museum and sweep record. A cross log exists at the end of it. A corresponding cross log exists on the exhibition board in front of each object. Visitors can press it to acquire all information of this work and record it in the scanner. They can record works in which they are interested or information about exhibits that they fail to read carefully because of time limit. Visitors can $\log$ in the museum website afterwards to download complete information of objects leaving a deep impression on them.

Another highlight in interactive design of the museum is the smart table with interactive screen provided in exhibition rooms of each floor. The smart screen has three characteristics:
Firstly the operation of interface is easily understood; secondly, the interface has extremely high sensitivity with zero delay and good user experience; thirdly, the relationship with exhibits is created through understanding of visitors and interaction. Visitors can independently design personalized patterns through 3D aided cartographic software. It can be professional or unrestrained. The interaction is more important to deepen the impression. Visitors can keep and record it in their visiting databases.

\section{Exhibition of Multimedia Interactiion}

Multimedia technology synthesizes and arranges information media like texts, graphics, images, sounds and videos in computer system. [4] It is applied to exhibition design of museum to alter static exhibition to dynamic exhibition, arouse visitors' interests and display stories of exhibits more visually. For example, in the exhibition of Riverside Scene at Qingming Festival in China Pavilion of Shanghai World Expo, the unique dynamic exhibition changes the original static image and leaves a deep impression on visitors. The digital multimedia technology is used to magnify the original painting as huge animation. Nearly 1,700 figures in the painting are activated by special effects. The whole painting flows with the effect of running water at the bottom of the wall and dialogue of figures on the boat. Visitors can clearly see more than 1,000 ancient Chinese figures in the painting. They are as natural as though they were living in the scenery that day alternates with night. Visitors are as if personally on the scene to experience the living environment of the ancients. Good interactive effects between visitors and exhibits have been reached. [5] The multimedia interactive exhibition brings various sensual pleasures for visitors, attracts their interests and stimulates their enthusiasm in acquisition of information.

\section{CONCLUSION}

The application of interactive design in museum exhibition realizes equal dialogue between human and objects. It arouses visitors' interests in exploration and acquisition of information and knowledge and leaves deep impressions on them. It alters the exhibition of single object in museums and provides opportunities for visitors to interact and share information. The center of service objects changes from "objects" to "human", furthest making museums transmit cultural information for the public.

\section{REFERENCES}

[1] Wang Hongjun. Basis of Chinese Museum Science [M], Shanghai Classics Publishing House, 2001

[2] [US] Jennifer Pries, Interactive Design-Surpass Human-machine Interaction $[\mathrm{M}]$, translated by Liu Xiaohui, Zhang Jing. Electronic Industry Press, Beijing, 2003, page 4

[3] [US] Jennifer Pries, Interactive Design-Surpass Human-machine Interaction $[\mathrm{M}]$, translated by Liu Xiaohui, Zhang Jing. Electronic Industry Press, Beijing, 2003, page 4

[4] Wang Zhixiang. Exhibition Design [M], Shanghai Donghua University Press, 2008

[5] Li Cong, Zhang Jian. New Trend of Interactive Exhibition Design in Museum [J], New Architecture, May 2014. 